\title{
EN TORNO AL CONCEPTO DE MUNICIPIO
}

\section{SU M A RIO}

1. El Municipio: concepto sociológico.

a) El Municipio es una célula social espontánea y una constante histórica.

b) La "sociología aplicada" y el Municipio: el urbanismo.

c) Clasificación social de los Municipios.

d) El concepto sociológico del Municipio: criterios de nuestra legislación.

2. El Municipio como categoría política.

a) Relaciones con el Estado.

b) Subordinación al mismo; naturaleza de la autonomía o autarquía municipal.

c) Concepto político del Municipio en nuestro derecho.

3. El Municipio como entidad administrativa.

a) Equiparación del Municipio a las entidades privadas.

b) Diferencias entre la administración municipal y la administración privada.

4. El Municipio como persona jurídica.

a) El concepto de persona de derecho público.

b) Personalidad jurídica del Municipio y del Ayuntamiento.

c) El Municipio como Corporación de Derecho páblico.

\section{I.-EL MUNICIPIO, CONCEPTO SOCIOLOGICO}

a) El Municipio es una célula social espontánea y una "constante histórica».

TESIS harto discutida por juristas y sociólogos es la referente al carácter natural o artificial del Municipio, sin que haya sido posible determinar científicamente hasta ahora, cuál de las opiniones expuestas goza de mayor autoridad. En una concepción sociológica pura es innegable que el Municipio es un grupo social, de igual manera que el hombre, antes que sujeto de derecho, es una individualidad física y psicológica; el Municipio, antes que Corporación o persona jurídica, es igualmente una realidad geopolítica. El Municipio 
es una célula social, como lo es la familia; una y otra constituyen, según decía José Antonio, unidades naturales de convivencia. Quizá el origen sociológico del Municipio no sea análogo al de la familia. pues ésta descansa en la comunidad de sangre y aquél se explica por las llamadas relaciones de vecindad; mas estas relaciones vecinales han dado lugar a una de las formas más importantes de asociación humana; probablemente es la modalidad más característica de organización y estructuración social.

San Agustín, que en opinión de Eugenio d'Ors fué quien aportara la noción de sociedad, como imagen conceptual, a la Historia de la cultura, fundamenta el orden social, la comunidad física y moral de los hombres, en la idea de ciudad; no es sólo el nombre o denominación de su obra ("La ciudad de Dios"), pues.también cuando, en los diferentes capítulos de ésta, señala el ejemplo de la conducta social de los hombres, lo hace pensando en una ciudad. Ya antes la filosofía ática había condensado la organización de la comunidad en la polis, considerando que ésta era la agrupación en donde converge la actividad social del hombre. Discutióse después si la "civitas" y la "poiis" fueron el antecedente sociológico del Municipio o del Estado; en cierto modo lo que equivale a la moderna ciudad son las ciudades griegas y romanas, que tienen aquella nomenclatura. Podemos, pues, decir que el Municipio es una "constante histórica", que se da en todas las épocas y edades, cuando son superados los tiempos de nomadismo y perpetua migración; es una realidad sociológica y una unidad natural que no corresponde exclusivamente a un régimen jurídico-político determinado. "En relación con el Municipio puede decirse que ninguna otra organización social, ningún otro ente político, incluso el Estado, presenta caracteres naturales tan profundos. Producto espontáneo de las condiciones geográficas y demográficas, sobre todo de la concentración de la población." Zanobini, "Administrazione locale" (tercera ed. 1936, pág. 25).

\section{b) La "sociologıa aplicada» y el Municipio; el Urbanismo.}

La idea sociológica del Municipio como entidad natural, de constante presencia en la Historia, la vemos lo mismo en "La política", de Aristóteles, que en los modernos autores norteamericanos. La obra aristotélica, a pesar de su profundidad filosófica, no desdeña el estudio de los problemas concretos que presenta la vida de la ciudad en el orden físico. Así, por ejemplo, trata del abastecimiento de aguas a las poblaciones, del trazado de calles, etc. Al çabo de los siglos esto ha llegado a convertirse en una ciencia especializada, que primero 
comenzó llamándose "Sociología aplicada" y después Urbanismo (City Planning, Städtbau). Alguna de estas medidas repercuten en la legislación. Así, en las llamadas leyes de ensanche, ley de mejora, saneamiento y reforma interior de poblaciones, en el Estatuto $\mathrm{Mu}$ nicipal y en la Ley Municipal vigente (artículos 105 y 118) se prevé la intervención de las autoridades sanitarias-centrales unas veces, provinciales otras-en los proyectos que tienen por objeto realizar determinadas reformas en el trazado de calles, plazas, etc. El propósito fundamentalmente perseguido con aquella ciencia es el mejoramiento del medio amibiente, no sólo desde el orden estético, sino, antes que nada, en el aspecto sanitario. Hasta tal punto interesan estos problemas, que no sólo en los tratados de urbanismo-Ward, J. B. Williams, Carrera Justiz, Baumeister-, sino que en las propias obras de gobierno y régimen municipal, especialmente en las obras anglosajonas, se dedican capítulos a estas cuestiones. Munro llega a decir, después de resaltar la importancia de los factores demográficos en la estructura sociológica del Municipio, que el "indice de mortalidad es el barómetro de la eficacia administrativa" (1). Goodnow señala a este respecto cómo en las ciudades industriales en donde predominan las fábricas textiles, hay una gran mortalidad infantil, debido quizá a las cunsecuencias demográficas del empleo de mujeres casadas pertenecientes a clases menesterosas en pesados trabajos industriales de aquellas fábricas (2).

Mas no es sólo el aspecto físico el que importa a los modernos escritores; también el orden moral ha sido objeto de preocupación por parte de aquéllos. Algunos señalaban aterrados cómo en determinados Municipios, los llamados Municipios urbanos o de gran densidad de población, el índice de moralidad acusa alarmante descenso. Wilcox (3) cree necesaria una intensa fiscalización de los espectáculos, una vigilancia de las horas libres ("control of leisure») de los habitantes

(1) MUNRO: "The Government of American Cities", cif. esp. el cap. II: The so:ial structure of the city, p. 40.

(2) GOODNOW: "Municipal Government", p. 30.31. Atendiendo a estos hechos y a otros intimamente ligados con el bienestar de la población surgieron algunas tendencias, por las que se atribuía al Municipio determinadas actividades en el campo de la Politica social. Don Adolfo POSADA cita a este respecto, entre otros, los trabajos de STIER-SOMLO ("Die rechtlichen Grundlagen der Kommunalen Sozialpolitik") y WEBER ("Die Grosstadt und ihre sozialen Probleme").

De toda esta politica social municipal, que en nuestro régimen local iba desde la inspección de establecimientos incómodos, peligrosos e insalubres (Reglamento de 27 de noviembre de 1925) hasta el sostenimiento de oficinas locales de colocación (L. de 27 de noviembre de 1931) queda boy bien poca cosa, pues a medida que la Política social se fué intensificando, y se consideran órganos principales de la misma el Estado de un lado y los Sindicatos de otro, la acción del Municipio a este respecto disminuyó sensiblementc.

(3) WILCOX: "The American City", 1911, p. 126. 
del Municipio; incluso considera este autor los peligros del vicio en las grandes ciudades en relación con los orígenes de la compleja cuestión social. Aún se llega a decir por J. A. Hobson (1) que el hombre que vive en esta clase de Municipios (las ciudades) no es más inteligente que el hombre del campo, pues si bien la serie de conocimientos de que carece éste y posee aquél, hace que se le otorgue al hombre de la ciudad una presunta superioridad intelectual, lo cierto es que en la mayoría de los casos esa pretendida superioridad no descansa sino en una cultura superficial.

Por lo tanto, al estudiar el Municipio en cualquiera de sus factores, creemos no debe prescindirse de su consideración sociológica y que una concepción jurídico-positivista del mismo pudiera conducir a la elaboración de leyes de régimen local, perfectas en lo que al ordenamiento jurídico se refiere, ineficaces en su aplicación práctica.

\section{c) Clasificación social de los Municipios.}

El primer hecho sociológico que debe tenerse en cuenta es el de la gran diversidad de Municipios; desde la gran urbe con sus ciudades satélites, hasta el pequeño poblado que por su escasa importancia no puede concedérsele categoría de Municipio, hay una enorme variedad; asimismo es importante la distinción de la naturaleza del Municipio por las actividades de la mayor parte de la población (industrial, mercantil, minera, agrícola, pesquera, etc.) (2).

Más interés tiene todavía para el régimen municipal el heche de la aglomeración o disgregación de la población que integra el Municipio, y cuya representación más exacta se da en la ciudad y en la aldea.

La primera la define Posada (3) como un fenómeno de aglomeración de gentes que viven juntas en estrecha vecindad; es un conjunto de casas, de habitaciones contiguamente dispuestas, formando núcleo de edificación, viviendas y servicios. En ésta, como él dice, una definición superficial de la ciudad, aunque tenga precedentes en algunos de nuestros Códigos medievales (Partida 7.", Título XXXIII, Ley $6 .{ }^{\mathrm{a}}$ ): "lugar que es cercado de los muros con los

(1) HOBSON: "The evolution of modern Capitalism", 1904, p. 339.

(2) CAETANo, en su "Direito Administrativo", Lisboa, 1936, señala cómo los Municipios pueden ser clasificados con arreglo a un punto de vista fiscal, al de población, o con arreglo a un criterio social. En este último sentido distingue el Municipio urbano, rural y mixto, y dentro de ls urbanos diferencia los industriales, comerciales, maritimos, mineros.

El régimen del Código administrativo portugués combina estos criterios: Primero distingue la clase: Municipio urbano, rural y mixto (Municipios rurales aptos para el turismo, estación balnearia, etc.); después distingue tres órdenes dentro de cada una de esas categorias.

(3) "Ei régimen counicipal de la ciudad moderna", tercera ed., p. 7. 
arrabales e los edificios que tienen con ellos". Los modernos autores al definir aquélla, recogen la idea de que la ciudad ocupa generalmente un área reducida de territorio (1); en efecto, el territorio edificado de la ciudad es relativamente pequeño, desde el momento que implica una concentración de población.

La aldea es, por el contrario, el fenómeno de diseminación de los habitantes del Municipio; las actividades de su población son generalmente agropecuarias y tienen una vida municipal menos intensa.

Decía Ihering que el pueblo ario, en sus orígenes, no conoció mas que la aldea. En la actualidad la aldea representa edificaciones más o menos aisladas unas de otras, sin solución de continuidad, pero constituyendo siempre un núcleo municipal; no deben confundirse con las granjas, cortijos, masías, etc.; éstos son núcleo de edificación y población totalmente aisladas; aquéllos son propiamente $\mathrm{Mu}$ nicipios, aunque a veces sólo alcanzan categoría de barrios, parroquias (2), anteiglesias, anejos, caseríos y demás categorías de "entidades locales menores".

Otro hecho sociológico que tienen en cuenta las leyes municipales es el de los medios económicos que posean los Municipios; si éstos tienen recursos "propios", con los que puedan ayudar a los vecinos de los mismos. Algunos Municipios españoles poseían tal cantidad de bienes comunales y de propios que, con harta razón pudo decirse, aquellos bienes constituían "el patrimonio de los pobres"; en estos Municipios no había mendigos ni pordioseros, pues los recursos municipales bastaban para sustentar casi durante todo el año a los que carecían de propiedades o posibilidades de trabajo. Esta situación se trastoca por completo al producirse en el siglo XIX un fenómeno desgraciado, la llamada desamortización de manos muertas, la cual, según sus defensores, implicaba consecuencias trascendentales en el orden jurídico, económico y político. Olvidaron por cierto las duras repercusiones sociales que aquélla llevaba consigo, pues si merced a la desamortización pudieron enriquecerse gran número de familias, los pobres quedaron en el mayor desamparo.

Junto al fenómeno de los Municipios "pudientes", es interesante considerar asimismo el de los "Municipios pobres", es decir, el de aquellos que carecen totalmente de medios económicos hasta el punto

(1) MUNRO, op. cit.. p. 29. "The Modenn City is roughly definable as a body of population bassed in a small aerea".

(2) CaE'rano, op. cit, dice que la Parroquia tiene más importancia social que el Munipio, si bien señala cómo la legislación portuguesa ha vacilado en otorgarles funciones adminis. trativas. 
de que han de agruparse con otros municipios para sostener sus servicios administrativos.

Hay por último una serie de fenómenos sociológicos complejos íntimamente relacionados con el Municipio, los cuales no podemos abordar en este estudio porque dilataríamos considerablemente los límites del mismo.

De lo expuesto se deduce que el Municipio, antes que persona jurídica, categoria política o entidad administrativa, es un grupo sociológico al par que una organización económica, y como tal tiene que ser considerada para su adecuada sistematización en el ordena. miento jurídico. Y no sólo es interesante la consideración sociológica para la esfera del Derecho; también lo es para la ordenación de su Hacienda y para el Gobierno y la Administración general del Estado.

d) El concepto sociológico del Municipio; criterios de nuestra legislación.

Como síntesis de las anteriores consideraciones podemos definir sociológicamente al Municipio comoagrupación natural de personas unidas por vínculos de vecindad para satisfacer las necesidades que exceden del orden familiar; esa agrupación se produce dentro de un territorio no excesivamente grande, existiendo una específica comunidad de bienes y una serie de obligatorias aportaciones para cumplir aquellos fines.

Como puede advertirse en la definición que proponemos, hay tres notas esenciales: una, la primera, es el carácter de agrupación natural. Decimos "agrupación" y no "asociación" porque este término trae la sugerencia de las uniones de personas que están contenidas en la Ley de Asociaciones. Es decir, que la palabra Asociación tiene un valor jurídico, en tanto que el término agrupación es un vocablo que dentro de su vaguedad e imprecisión refleja el fenómeno del "grupo social", que es precisamente lo que se trata de referir. Al añadir el adjetivo natural se advierte que ese "grupo social" puede surgir espontáneamente.

Otra de las notas fundamentales que en nuestro sentir debe recoger una definición sociológica del Municipio es la idea de que el conjunto de personas que lo integran están unidas entre sí por vinculos de vecindad; por estar tan próximas unas viviendas de otras, por congregarse $\tan$ estrechamente los alojamientos, surgen indefectiblemente relaciones de mutua cooperación y ayuda para cumplir ciertos fines. Incluso en las aldeas de población diseminada se manifies$\tan$ esas relaciones de vecindad. 
La tercera nota fundamental la constituye la naturaleza de esos fines. Cuando se habla de relaciones de vecindad en el lenguaje corriente, e incluso cuando se hace referencia a este término en alguna disposición legal (art. 2 de la Ley de Contrato de Trabajo), se alude a aquellos que tienen por objeto satisfacer necesidades domésticas o de empresas que requieren circunstancialmente la colaboración de personas que viven en casa contigua a la nuestra. Pero los fines que tiende a satisfacer el Municipio son aquellos que excedan de la esfera propiamente doméstica. No basta para cumplir estos fines ia coope. ración momentánea y circunstancial, sino una colaboración sistemática y organizada, pues son fines constantes, son necesidades permanentes que no puede cumplir por sí una familia, sino que requieren la aportación continua y duradera de comunes esfuerzos.

Junto a estas tres notas esenciales, estimamos que deben tomarse en consideración los otros dos elementos accesorios del concepto sociológico del Municipio: a), que ese grupo social habita en un término territorial de dimensiones más o menos reducidas, y b), que existen bienes comunes afectos al cumplimiento de aquellos fines, y que se establece además una contribución forzosa no sólo en medios económicos, sino a veces también en esfuerzos personales (prestaciones personales obligatorias), enderezados a la satisfacción de las expresadas necesidades.

Hay que advertir que este concepto sociológico se recoge en algunas disposiciones legales de nuestras leyes y proyectos de régimen local. Claro es que puede discutirse la necesidad de que al frente de una ley municipal se defina el Municipio; una definición sociológica no tiene en rigor directas consecuencias jurídicas; pero de formularla en la ley convendrá recoger en la fórmula los rasgos esenciales y específicos de la entidad definida. En todo caso, la fórmula, una vez consignada en la ley, puede servir para conocer el concepto o la idea del legislador y nos ofrecerá su visión de la comunidad municipal (1).

Veamos lo que dicen los textos legales. La ley de 1877 definía en su art. $1 .^{\circ}$ el Municipio como la "asociación legal de todas las personas que residen en un término municipal”. Además, según el artículo 2. ", "es término municipal el territorio a que se extiende la acción administrativa de un Ayuntamiento". En el proyecto de Bases de Maura de 1903 se decía: "Forma Municipio la asociación natural y legal de todas las personas que residen en un término, o sea el territorio a que se extiende la acción administrativa de su Ayuntamien-

(1) POSADA: Op. cit., p. 59. 
to." Según el proyecto de reforma de 1907 (Maura-La Cierva): "Forma Municipio la asociación natural y legal de familias y casas dentro del término a que alcanza la jurisdicción de su Ayuntamiento." En las Bases presentadas a las Cortes en 1912 por Canalejas y Barroso se definía el Municipio como la "sociedad natural, reconocida por la ley, establecida en un término territorial definido por las relaciones de vecindad, y al cual alcanza la jurisdicción de un Ayuntamiento".

Con cierta analogía, la ley Municipal de 1935 dice en su artículo $2 .^{\circ}$ que el "Municipio es una asociación natural de carácter público de personas y bienes constituída por necesarias relaciones de vecindad y domicilio dentro de un territorio determinado". El Proyecto de Código de Administración local presentado en 1941 y que, según declaró recientemente el Caudillo, ha de ser sometido a las próximas Cortes, define en el art. 10 el Municipio, diciendo que es la "comunidad natural reconocida por la ley, de familias, empresas e instituciones, unidas por el vínculo de vecindad y establecidas en un determinado territorio".

Señálase como fines del Municipio en el segundo párrafo del citado artículo: "la realización de los fines que trascienden inmediatamente de la vida familiar..."

\section{II.-EL MUNICIPIO COMO CATEGORIA POLITICA}

\section{a) Relaciones del Municipio con el Estado.}

El Municipio decimos que es una categoría política. En primer lugar porque se manifiesta en cierto sentido dentro de algunos de los vínculos que sirven de integración a la comunidad política. EI Municipio es una parte de esta comunidad; es una célula de la misma. En segundo lugar, el Municipio tiene relaciones con otras entidades políticas y especialmente con el Estado.

Dice Rowe (Problems of City Government) que las relaciones entre el Municipio y el Estado son tan varias, y en muchos casos tan imprecisas, que es difícil formular principios generales aplicables a todos los regímenes. Hay, sin embargo, tres ideas fundamentales que perviven en toda organización municipal. Primera: El Municipio es una entidad pública. Segunda: Es una entidad subordinada al Estado. Tercera: Goza de cierta autonomía o autarquía administrativa.

Cuando decimos que el Municipio es una entidad pública, queremos significar también que es una pequeña comunidad política en 
cuanto es órgano titular de fines de interés general y aun de fines políticos menores (1).

Ahora bien, esos fines políticos han de estar en armonía con los fines del Estado. El Municipio es, pues, titular de fines políticos. Ello no quiere decir que la entidad municipal sea una parte del Estado, pues si bien la Ciencia Política moderna no toma en consideración la tesis rousseaunianoliberal de que el Estado es una mera suma gregaria de individuos, tampoco acepta la formulada por los teóricos del Estado integral, que ven en aquel una concatenación de entidades territoriales menores (2).

Por lo tanto, la dirección política del Estado penetra en la propia vida municipal; mas también a su vez, el Municipio es órgano ejecutor de la actividad política de la comunidad estatal. Ya Goodnow (3) señalaba cómo el régimen municipal refleja en parte el pensamiento político de la nación, y constituye un sector importante del sistema general de gobierno. El propio Goodnow y otros autores recogen el hecho de que el Municipio ha sido un verdadero laboratorio de derecho público y $\mathrm{S}$. Royo Villanova (4) pone de manifiesto cómo las grandes reformas municipales en Alemania sirvieron de base para la unificación nacional; los hombres que trazaron las bases de la organización política de Alemania -Stein, Preuss-fueron los que realizaron o prepararon las bases de la reforma local.

En resumen, la organización del Municipio es uno de los problemas fundamentales de la organización del Estado (5).

(1) Cif. art. 1.0 de la Ley Munic:pal alemana en WEIDEMANN: "Die Deutsche Gemeindeordnung. Kommentar". Segunda ed., 1937.

(2) Los tratadistas alemanes (HOEHN, HUBER, MAUNZ y KOTTGEN, entre otros) insisten en afirmar que el Estado Nacional-socialista no es un Estado plural, no es un compuesto de otras entidades territoriales. Existen, si, entidades secundarias que gozan de una capacidad de ordenación propia, ejerciendo una relativa autonomia administrativa, concurriendo en esta forma a la estructuración general del Reich; pero ello no supone la existencia de un Estado pluralista, porque los Municipios constituidos con esta autonomía no gozan de una ordenación distinta y separada de la ordenación general de la colectividad política, sino que son una parte de este ordenamiento, al que están incorporados, y precisamente por estar sometidos a la voluntad del Reich se limitan a administrar los intereses que le han sido confiados por la "Führung". A. MESA SF.GURA: “La unificación del régimen político y administrativo alemán". Revista de Estudios de Administración local, n. 2, p. 56 .

(3) "Municipal Problems", 1907, p. 15 y sigts.

(4) Segisnumdo ROYO VILLANOVA: "El Derecho municipal prusiano". Revista Derecho público, 1934.

(5) J. GASCON Y MARIN: “Administración municipal", en la Rev. Las Ciencias, 1939, n. 1. "Preocupa, con razón, en todos los Estados el problema de la vida municipal. No en balde el Municipio es la entidad natural, y la eficaz actuación municipal constituye base esencial de la vida próspera de la nación. No siendo de extrañar que, tanto países autoritarios como democrá. ticos, vengan prestando solícita atención a la organización y regulación jurídica de la actividad comunal, tanto en la ciudad como en el pueblo y aldea." 


\section{b) Subordinación del Municipio al Estado.}

El Municipio, decíamos, es una entidad subordinada al Estado; éste puede ampliar o restringir los fines y funciones de aquél; puede disminuir o extender las facultades o poderes que le son reconosidos; puede asimismo el Estado cuidar de que el Municipio cumpla los fines que le están encomendados y corresponderle, por tanto, fiscalizar la actividad de los organismos municipales. Sin embargo, señalamos también cómo el Municipio goza de autonomía o autarquía administrativa, porque aquella fiscalización del Estado no se opone a esta autonomía.

Han sido últimamente los autores alemanes e italianos los que pusieran de relieve la supervivencia de la autonomía municipal en las reformas de régimen local llevadas a cabo en los respectivos países (1).

En definitiva, el Municipio como categoría política es una comunidad subordinada que realiza fines coincidentes con los del Estado.

La Ley Municipal Alemana señala cómo el Municipio ha de cumplir sus fines en conformidad con los de la comunidad politica superior y la Administración de los mismos se ha de realizar en armonía con los fines del Estado (2).

Algunos autores italianos expresan asimismo la idea de la cooperación del Municipio en las tareas político administrativas del Estado, al esbozar su teoría de los "entes auxiliares".

(1) KOELLRELTTER: "Deutsches Verwaltungsrecht", insiste en la importancia del concepto de autonomía o autoadministración, profundamente arraigada, dice, en el espíritu del pueblo alemán. No desaparece en el nuevo Estado, incluso se le da nuevas y vitales proyecciones en el campo económico $\mathrm{y}$ en otros aspectos de la Administración institucional.

Para la determinación conceptual de ese término recuerda la diferencia ya establecida por la doctrina liberal-positivista entre autonomía politica y autonomia adninistrativa. La primera, dice, no tiene razón de ser en el nuevo Estado, si se la definia como la participación directa de los ciudadanos en la gestión y dirección de los órganos administrativos.

FRANK defiende asimismo la Selbsverwaltung y dice que "el sistema ministerial superburocratizado y centralizado de la Administración francesa no es apropiado al pueblo alemán. El Es. tado unitario alemán no significa unificación esquemática."

SALEMI: "La riforma communale e l'autarchia en Scritti in onore di SANTI ROMANO, 1940, señala dos tendencias: la extremista, que quiere abolir el concepto de autarquia, y la tradicional. representada por RANELLETTI, ROMANO y ZANOBINI, que la conserva.

La autarquía municipal en el régimen legal fascista presenta estas dos notas: a), La designación de funcionarios se hace por el Gobierno; b) E.l Municipio conserva su personalidad juridica. El con. trol del Estado no es la antítesis de esta personalidad, sino un elemento de la misma.

Claro es que el ejercicio de aquél limita la esfera de esa personalidad, la cual se aleja de la figura juridica de la corporación. para revestir otros requisitos más próximos a la institución. La autarquía municipal que exigia como regla un control de legitimidad y excepcionalmente un con. trol de oportunidad, hoy tiene como normal este iltimo, al igual que otros entes publicos (institucionaites). En resumen. sigue la autarquia municipal, si bien acuse mayor ingerencia estatal.

(2) Cif. WEIDENANN, op. cit., art. $3^{\circ} \mathrm{d}$ la Ley. 


\section{c) Concepto político del Municipio en nuestro Derecho.}

En nuestro Derecho municipal la noción del Municipio como entidad política fué recogida de una manera un tanto velada e incompleta. Desde luego, no responde a la importancia política que a lo largo del XIX tuvieron las cuestiones de régimen municipal. No es menester recordar cómo un simple problema de organización municipal (la designación de Alcaldes), dió lugar a un conato de movimiento revolucionario. Los propósitos de reforma municipal ocuparon un primer plano en todos los intentos de constitución política; desde 1812 hasta 1931, pasando por la experiencia del Estatuto y los proyectos de Maura, La Cierva y Canalejas, se ha reflejado esa trayectoria. Mas, como decíamos, el problema no se había planteado de una manera explícita en los textos legales hasta el último Proyecto de Código de Gobierno y Administración local de 1941. El artículo $1 .^{\circ}$ de este Proyecto dice que los "Municipios y la Agrupación territorial de éstos en provincias forman la estructura política administrativa local de la Nación española", añadiendo en el art. $2 .^{\circ}$ que "el Estado reconoce y ampara la existencia y personalidad de las autarquías locales, dentro de la debida subordinación jerárquica a su superior Poder". En el art. 6..$^{\circ}$ se declara que "Ia acciớn de las Administraciones locales no sólo ha de referirse a las órbitas de sus intereses peculiares, ajustados a los fines que las leyes les asignan, sino que orientará e impulsará las aptitudes morales de la comunidad regida hacia los designios que imponen los principios cardinales del Estado Nacional", y finalmente, en el artículo 11, se dice que "el Municipio asumirá las funciones y servicios de la Administración central que el Estado le encomiende, observándose siempre a este respecto lo dispuesto en el árt. $5 .^{\circ}$ de este Código".

\section{III.-EL MUNICIPIO COMO ENTIDAD ADMINISTRATIVA}

\section{a) Equiparación del Municipio a las entidades privadas.}

Desde el momento que estimamos que el Municipio es una enti. dad administrativa, hay que ver en él una organización titular de ciertos servicios públicos. La forma de prestar estos servicios ha sido materia también harto discutida, pues algunos han pretendido equiparar el Municipio y la empresa mercantil (1).. De una parte fué la injerencia de las entidades municipales en la prestación de

(1) En esta nisma revista, núm. 2, p. 63 y sig., el art. del Sr. CIURANA FERNANDEZ 
algunos servicios que venían siendo realizados por empresas privadas; aquéllos llegan a recabar totalmente el servicio-municipalización-, o bien intervienen de una manera parcial en la dirección de aquellos conjuntamente con las empresas o compañías que tienen la gestión de los mismos (régimen de economía mixta, régie interessée, Gemeinswirtschaft).

De otra parte, la equiparación de los Municipios y las entidades privadas fué debido a que se adoptaran por aquellos algunos de los métodos de gestión mercantil e industrial. La organización científica del trabajo fué así otra de las causas de esa aproximación entre la Administración pública y. la privada, pues los excelentes éxitos conseguidos en esta última, merced a los nuevos métodos de organización, hizo que se aplicaran también en las entidades públicas, dando lugar a una verdadera "Organización científica del Trabajo Administrativo" (fayolismo).

Y fué precisamente en la Administración municipal donde primero se implantaron los nuevos métodos de organización y los procedimientos de gestión, patentizando con ello la semejanza entre las empresas racionalizadas y algunos municipios.

Sin embargo, han sido los propios americanos los que, a pesar de haber inventado esas formas tan peculiares de administración municipal, llevándolo hasta sus más últimas consecuencias, en el sistema llamado "gobierno por comisión" y "gobierno por gerente", los que dicen que el Municipio no puede ser conceptuado como una "business corporation" (1).

\section{b) Diferencias entre la Administración Municipal y la Administración privada.}

El Municipio es una entidad administrativa, que se rige por los principios de la Administración pública, distintos esencialmente de los de la administración privada. Las diferencias han sido expuestas multitud de veces; podríamos decir que sustancialmente se basan en estas tres características fundamentales: $10^{\circ}$ Por los fines; la empresa privada busca la perfección de los servicios que presta, lo hace para satisfacer a sus clientes y aumentar así sus ganancias; en la empresa pública la mejora de los servicios es objetivo constante, independientemente de que los habitantes del $\mathrm{Mu}$ nicipio contribuyan en mayor o menor proporción al aumento de

(1) GOODNOW, Municipal Froblems: "If the city is a mere business corporation, as a many have said that it is, should be governed in accordance with the principles of business. If, on the other hand, it is a governamental organ, it should be goberned in accordance with tb: principles of government." 
los ingresos municipales. 2. ${ }^{\circ}$ Por sus derechos, potestades, privilegios y exenciones tributarias. El Municipio tiene facultades coercitivas, un poder de ordenanza, puede dictar prescripciones generales obligatorias y es además títular de lo que los alemanes llaman la "coacción administrativa" (Werwaltungszwang). Aparte de estas potestades de derecho público, que no tiene la empresa prirada, las entidades municipales son de carácter obligatorio. El vecino no tiene facultad para pertenecer o no pertenecer al Municipio, sino que forzosamente ha de estar adscrito al mismo. De igual manera que un hombre es súbdito de un estado, es también vecino de un Municipio. $Y$ si en la esfera estatal existe el extranjero con un Estatuto especial de derechos y deberes, en la esfera municipal se da la figura del "transeúnte" con una situación asimismo específica. 3.9 Por el régimen jurídico de sus bienes. El Municipio es titular de dominio público; pero además tiene un patrimonio sometido a un régimen especial. $Y$ además, su capacidad de obrar en el orden patrimonial es harto restringida. El Municipio no tiene "la agilidad mercantil" de las empresas privadas. Se ha equiparado su capacidad jurídica a la de una persona jurídica que tiene disminuída su capacidad de obrar, incluso sus actos de pura administración están sometidos a una triple conjunción de voluntades (la del Al. calde, la del Interventor y la del Depositario). Los contratos que celebra el Ayuntamiento se someten a ciertas y determinadas formalidades. Mayores son todavía las medidas cautelares que se adoptan contra una libre disposición o enajenación de sus bienes, o la utilización del crédito. Por último, la forma de procurarse sus ingresos con arreglo a los métodos de la economía pública, (la imposición y la tasación) nos hace ver cuán lejos está el Municipio de poder ser considerado como una entidad administrativa privada.

Ahora bien, el hecho de diferenciar el Municipio de las empresas mercantiles, no quiere decir que los métodos y procedimientos derivados de la racionalización del trabajo no pudieran ser incorporados parcialmente al procedimiento. administrativo municipal, pues, como antes indicábamos, en algunos casos así se ha hecho, y sus re. sultados fueron satisfactorios.

En resumen, podríamos decir que el Municipio en cuanto es una entidad administrativa de carácter público se halla sometido a un régimen legal contenido en las leyes municipales. Sin embargo, al reconocer al Municipio facultades autárquicas de organización y funcionamiento dentro de los límites establecidos por la ley, cabe 
que aquél acepte métodos de gestión, que en ciertos casos pueden equipararse a los de empresa privada.

\section{IV.-EL MUNICIPIO COMO PERSONA JURIDICA}

\section{a) El concepto de persona en Derecho público.}

Por último, decíamos que el Municipio es una unidad jurídica. El Municipio es una persona colectiva de derecho público y, en consecuencia, sujeto de derechos y obligaciones de carácter privado; si bien no todas las personas de Derecho privado tienen potestades de Derecho público, en cambio, todas las entidades públicas tienen capacidad jurídica y capacidad de obrar en el ámbito del Derecho privado patrimonial. Como hemos apuntado en otro lugar (1), el origen de la personalidad jurídica de muchas entidades públicas surgió por la existencia de un patrimonio o también por la perspectiva de ser titular de una propiedad y de poder adquirir derechos y contraer obligaciones. Ahora bien, esta personalidad de las entidades públicas no es uniforme. De aquí el que en vez de hablarse de persona de Derecho público, como si se tratara de una categoría única, se fué elaborando una doctrina de las "personas", y de igual manera que en derecho privado, el concepto de persona no refleja una idea abstracta y uniforme, sino que hay variedad de matices, desde los que recoge el sistema romanista de los "status", hasta las diferentes modificaciones de la capacidad de obrar, también en Derecho público, con cierta simetría sistemática, encontramos: una persona jurídica con capacidad plena, el Fstado, la Administración central, y luego, una serie de categorías que, si bien en ciertos casos constituyen grupos homogéneos y perfectamente definidos, en la llamada Administración local, otras veces se distingue en grupos variadísimos de características tan diversas, que tienden a la dispersión, resultando muy difícil clasificarlos, pues a duras penas puede ser recogida dentro de la llamada Administración institucional o corporativa.

Así, pues, mientras en Derecho privado la naturaleza y la capacidad de las distintas personas tiene una disciplina uniforme y sistemática, según los diferentes estados o situaciones por que atraviesa, en Derecho público la condición de cada persona jurídica no siempre se ha establecido de una manera clara y uniforme.

(1) Cif. nuestro trabajo ei prenui "froblemas de Administración Corporativa", en la Revista dc Estudios Politicos. 


\section{b) Personalidad juridica del Municipio y del Ayuntamiento:}

El Municipio, considerado en el ámbito del Derecho, es una "persona jurídica". Constituye una de las entidades territoriales. La legislación española venía distinguiendo a este respecto Municipio y Ayuntamiento. De la misma manera que se hablaba de Nación y Estado y se define éste como la personificación jurídica de la $\mathrm{Na-}$ ción, nuestras leyes municipales diferenciaban Municipio y Ayuntamiento, considerando a éste como la "representación legal del $\mathrm{Mu}$ nicipio". En la ley vigente de 1935, el art. 37 dice que "el Ayunțamiento $y$, en su caso, el Concejo abierto, es el órgano supremo de la Administración municipal, al que corresponde la dirección y gobierno de los intereses morales y materiales del Municipio; ostenta su representación legal y tiene el carácter de Corporación de Derecho público; que encarna la jurisdicción municipal”. Sin embargo, el art. $3 .^{\circ}$ dice que "Los Municipios y las entidades locales menores tendrán plena capacidad jurídica dentro de los límites y con los requisitos establecidos en las leyes. Podrán, en consecuencia, adquirir, reivindicar, conservar y enajenar bienes de todas clases, celebrar contratos, establecer y explotar toda clase de obras y servicios públicós, obligarse y ejercitar recursos administrativos, así como acciones civiles, criminales, contencioso-administrativas y las demás contenidas en las leyes. Las agrupaciones intermunicipales tendrán plena capacidad jurídica, con arreglo a los Estatutos, para el cumplimiento de sus peculiares fines".

¿Qué quiere decir esto? ¿Es que existen dos clases de personas jurídicas, una el Municipio, otra el Ayuntamiento? Como fácilmente se comprende, no es admisible esta solución; en realidad, lo que sucede es que el Ayuntamiento es el organismo en el que encarna el ejercicio de esa personalidad; es, como dice la ley, el representante legal. Sin embargo, el problema se complica si nos planteamos la idea del ejercicio no sólo de derechos subjetivos, sino también de potestades (1). ¿En quién encarna, por ejemplo, la facultad de acordar actos que, conforme al art. 94 de la Ley Municipal, han de ser acordados mediante referendum? Según dicho artículo, para enajenar bienes de aprovechamiento común, o cuyo importe exceda del 20 por 100 del presupuesto ordinario de ingresos, o para concluir ciertos convenios de quita y espera, o para otorgar determinadas concesiones o arrendamientos, el acuerdo del Ayuntamiento ha de

(1) Véase la breve monografía de G. D. FERRI: "Sul concetto di facoltà in Diritto pubblico", 1939. 
ser ratificado por referendum; es decir, por votación popular. ¿Es que en este caso podía decirse que el Cuerpo electoral del Municipio es una persona jurídica? No; pues innegablemente la personalidad jurídica del Municipio es una; lo que sucede es que el ejercicio de su capacidad de obrar está conferida a diferentes órganos.

\title{
c) El Munıcipıo como Corporación de Derecho Público.
}

El proyecto de Código de Administración local dice que el $\mathrm{Mu}$ nicipio es una Corporación de 'Derecho Público (art. 10). Es decir, que se reforma el régimen legal vigente desde el momento que es al Municipio y no al Ayuntamiento al que se considera como tal Corporación de Derecho Público. El art. $4 .^{\circ}$ del Proyecto reconoce la capacidad jurídica para cumplir sus fines "con sujección a los límites y con los requisitos establecidos en las leyes".

Sería muy interesante determinar cuáles son los derechos y facultades del Municipio como Corporación de Derecho Público; es éste un concepto tan nuevo en nuestro Derećho, que la doctrina apenas si ha esbozado las directrices del mismo. Hay que tener en cuenta que el régimen legal de la Corporación de Derecho Público se desarrolla en un entrecruzamiento de potestades y un escalonamiento de derechos; la autarquía administrativa se conjuga con una fiscalización estatal; mas no prolonguemos los límites ya dilatados del presente trabajo; el régimen del Municipio como Corporación de Derecho Público bien merece que se le haga objeto de otro artículo.

\author{
Eugenio Perez Botija \\ Catedrático de Derecho Administrativo \\ de la Universidad de Murcia.
}

